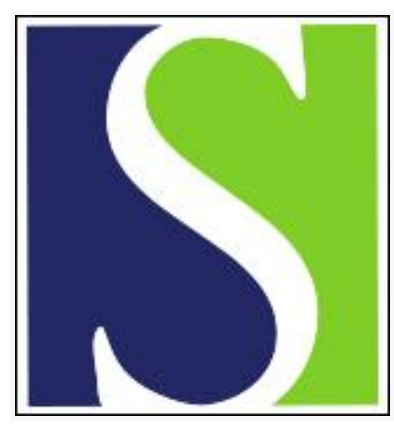

Scand J Work Environ Health 1976;2(3):129-139

https://doi.org/10.5271/sjweh.2811

Issue date: Sep 1976

Disturbances in psychological functions of workers occupationally exposed to styrene.

by Lindström $\mathrm{K}$, Härkönen $\mathrm{H}$, Hernberg $\mathrm{S}$

Key terms: disturbance; mandelic acid; mandelic acid excretion; occupational exposure; polyester plastic; psychological function; styrene; styrene exposure; worker

This article in PubMed: www.ncbi.nlm.nih.gov/pubmed/973126

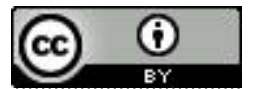




\title{
Disturbances in psychological functions of workers occupationally exposed to styrene
}

\author{
by KARI LINDSTRÖM, Ph.L., HANNU HÄRKÖNEN, M.D., and \\ SVEN HERNBERG, M.D. ${ }^{1}$
}

\begin{abstract}
LINDSTRÖM, K., HÄRKÖNEN, H. and HERNBERG, S. Disturbances in psychological functions of workers occupationally exposed to styrene. Scand. $j$. work environ. \& health 3 (1976) 129-139. The relationship between long-term occupational styrene exposure and disturbances in psychological functions was studied. The exposed group consisted of 98 male workers exposed to styrene in the manufacture of polyester plastic products, and the comparison group comprised 43 concrete reinforcement workers. The duration of exposure in years and the mean mandelic acid concentration in urine (five determinations during 5 weeks before the clinical examination) and the cumulative dose of exposure were used as the indicators of exposure. The psychological functions studied were intelligence, visuomotor speed, visuomotor accuracy, memory, vigilance, and psychomotor performance. Some personality test variables were also included. In a group comparison two variables (visuomotor inaccuracy and poor psychomotor performance) out of 20 showed statistically significant differences and characterized the styrene exposed group. These findings were confirmed when workers with low and high styrene exposure were compared. One variable measuring visuomotor speed and another measuring visual memory were related to the duration of exposure $(\mathrm{R}=0.28$, $\mathrm{p}<0.05)$. In a multiple regression analysis disturbances in visuomotor accuracy, poor psychomotor performance, and lowered vigilance proved to have some connection with a high mandelic acid concentration $(R=0.49, \mathrm{p}<0.01)$. In addition workers with disturbances in visuomotor accuracy and slight disturbances in visuomotor speed had higher mandelic acid concentrations when compared with those workers without any deterioration. The results indicate that disturbances in visuomotor accuracy and, to a lesser degree, in psychomotor performance are the main findings measured by test methods used in this study and related to one indicator of styrene exposure, mandelic acid concentration. The psychological methods used revealed subclinical symptoms related to exposure, and they should aid in making group diagnoses, e.g., when additional information is needed for the determination of the threshold limit value. The deterioration found in visuomotor accuracy could be related to lowered safety in work and traffic.
\end{abstract}

Key words: styrene exposure, polyester plastic, mandelic acid excretion, psychological functions.

Various studies have demonstrated adverse effects of many industrial solvents on the central nervous system and psy-

1 Institute of Occupational Health, Helsinki, Finland.

Reprint requests to: Mr. Kari Lindström, Institute of Occupational Health, Haartmaninkatu 1, FIN-00290 Helsinki 29, Finland. chological functions. However, psychological studies in this field are quite new, and the manner of approach varies greatly between different countries. There is at present no established research strategy which reveals the toxic effects on mental functions. Experimental approaches have been the most popular $(4,5,15,17,19)$, and many such studies have been directed 
towards illustrating the adverse effects on different visual, psychomotor, and memory functions. Another group of studies has dealt with the long-term effects of occupational exposure to solvents. These attempts to estimate the prevalence of the organic psychosyndrome among groups of workers exposed to various solvents represent the beginning of psychological studies in this field $(1,13)$. The studies showed that a broad range of psychological functions are severely affected by solvents.

The psychological disturbances caused by long-term carbon disulfide exposure (8) proved to be severe for performances involving visuomotor speed, manual dexterity, and intelligence. Furthermore, qualitative differences were found between groups with manifest and latent carbon disulfide poisoning. In addition clear and widespread disturbances in psychological functions, although not so severe as in the carbon disulfide study, have been found in workers exposed to various solvents (12). These workers had been diagnosed as having an occupational disease, or they had been referred to a periodical health examination because of considerable solvent exposure at work. Sensorimotor speed performances and psychomotor performances showed the clearest disturbances among workers with a long duration and a high intensity of exposure.

Different authors have studied the adverse effects of short-term styrene exposure under laboratory conditions $(5,14$, 16). In these investigations simple and complex reaction time, perceptual speed, and manual dexterity were studied. Oltramare et al. (14) found a prolongation in simple reaction time and complex reaction time after exposure to $50 \mathrm{ppm}$ and 100 ppm of styrene, respectively. Gamberale et al. (5) showed some evidence of the noxious effects of $350 \mathrm{ppm}$ of styrene on perceptual speed. Finally Stewart et al. (16) disclosed that manual dexterity seemed affected in most subjects after $50 \mathrm{~min}$ of exposure to $375 \mathrm{ppm}$ of styrene.

The previously discussed studies do not consider the reversibility and duration of the findings, and the authors are very cautious in drawing conclusions. However, some suggestions have been presented. For example, Oltramare et al. (14) stated that the threshold limit value of styrene should be under $50 \mathrm{ppm}$ because of the deterioration found in psychological functions.

Reaction time has also been studied in epidemiologic studies dealing with occupational styrene exposure $(6,7)$. Götell et al. (7) found that styrene exposure over $150 \mathrm{ppm}$ prolonged reaction time. Furthermore Gamberale et al. (6) showed that occupational styrene exposure caused deterioration in reaction time over time and produced reaction time irregularity. The changes were measurable both before and after the work shift.

The earlier studies dealing with the psychological effects of styrene exposure do not provide all the information needed about the adverse effects of occupational styrene exposure on different psychological functions. Therefore we have studied the differences between the psychological functions of workers exposed to styrene and the psychological functions of workers without any noticeable chemical exposure affecting the central nervous system and determined the relationship between the psychological functions measured and the duration and intensity of styrene exposure.

\section{MATERIAL AND METHODS}

\section{Subjects}

The subjects were 98 male workers employed by 24 manufacturers of reinforced polyester plastic products in southern Finland. The workers spread the polyester resin by hand. Their ages ranged from 16 to 54 years (mean 29.6, SD 7.4).

We obtained information about health history, symptoms, and use of drugs from the subjects with a questionnaire and submitted the subjects to a clinical, neurophysiological, and psychological examination. None had diabetes, epilepsy, or a neurological disease or a history of unconsciousness lasting more than half an hour.

A comparison group was formed of 43 male concrete reinforcement workers, 19 to 45 years of age (mean 33.4, SD 7.7) without any styrene exposure. We chose 
this group because of its similarity with the exposed group in respect to age distribution, educational level, and geographical location. No one in the group had suffered from a neurological disease or had a history of unconsciousness lasting for longer than half an hour. The same psychologist tested the group at nearly the same time as the styrene exposed group.

\section{Exposure}

The duration of exposure (history of work with reinforced polyester plastic fabrics) was determined by the number of years the subjects were exposed to styrene. The exposure period ranged from 0.5 to 14 years (mean 4.9, $\mathrm{SD} 3.2$ ) (fig. 1).

We used the concentration of mandelic acid in urine as the measure of the intensity of styrene exposure (2). The urine samples were collected from every subject after $8 \mathrm{~h}$ of styrene exposure once a week on consecutive workdays for 5 weeks prior to the clinical examination.

The urine samples of the first 47 subjects were analyzed for the mandelic acid concentration by the modified colorimetric method of Ohtsuji and Ikeda (11); and the samples from 51 workers, with a gas chromatographic method (3). We then transformed the results of both methods to the same scale (3) and used the means of the five weekly measurements to estimate the intensity of individual styrene exposure. The mandelic acid concentration (mean of the individual measurements) varied from 7 to $4,715 \mathrm{mg} / \mathrm{l}$ (fig. 2).

\section{Test methods}

Almost the same test battery was used as that employed in examining the psychological effects of carbon disulfide and various other solvents $(8,12)$. The classification of test variables was primarily based on results of factor analyses performed with practically the same variables used in a carbon disulfide study (10). The functions measured were general intelligence, visuomotor speed, visuomotor accuracy, memory, vigilance, and psychomotor performance. The tests, variables, and test scores are shown in table 1.
Most of the test methods have been described in detail elsewhere (9). At the time of examination the intensity of exposure was not known to the examiner.

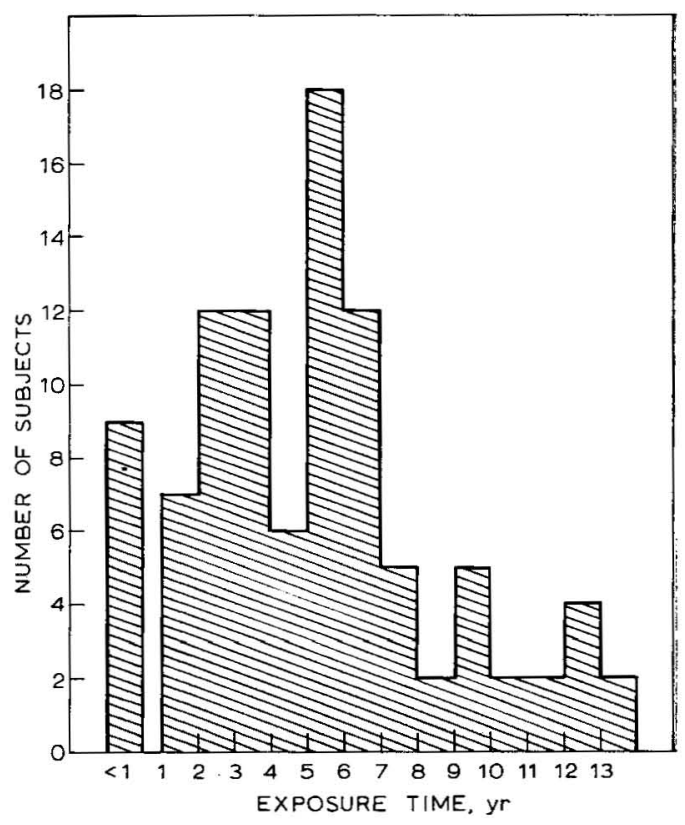

Fig. 1. Distribution of duration of exposure to styrene in the exposed group.

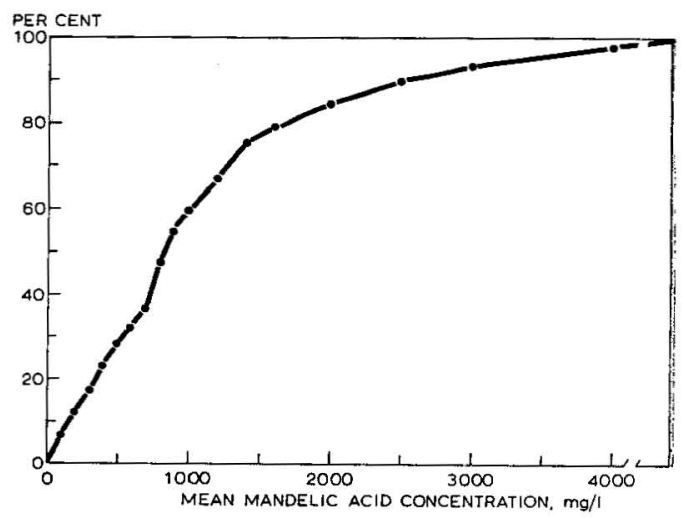

Fig. 2. Cumulative distribution of the mean mandelic acid concentration of five measurements. 
Table 1. The tests, variables and scores used to measure the psychological functions studied.

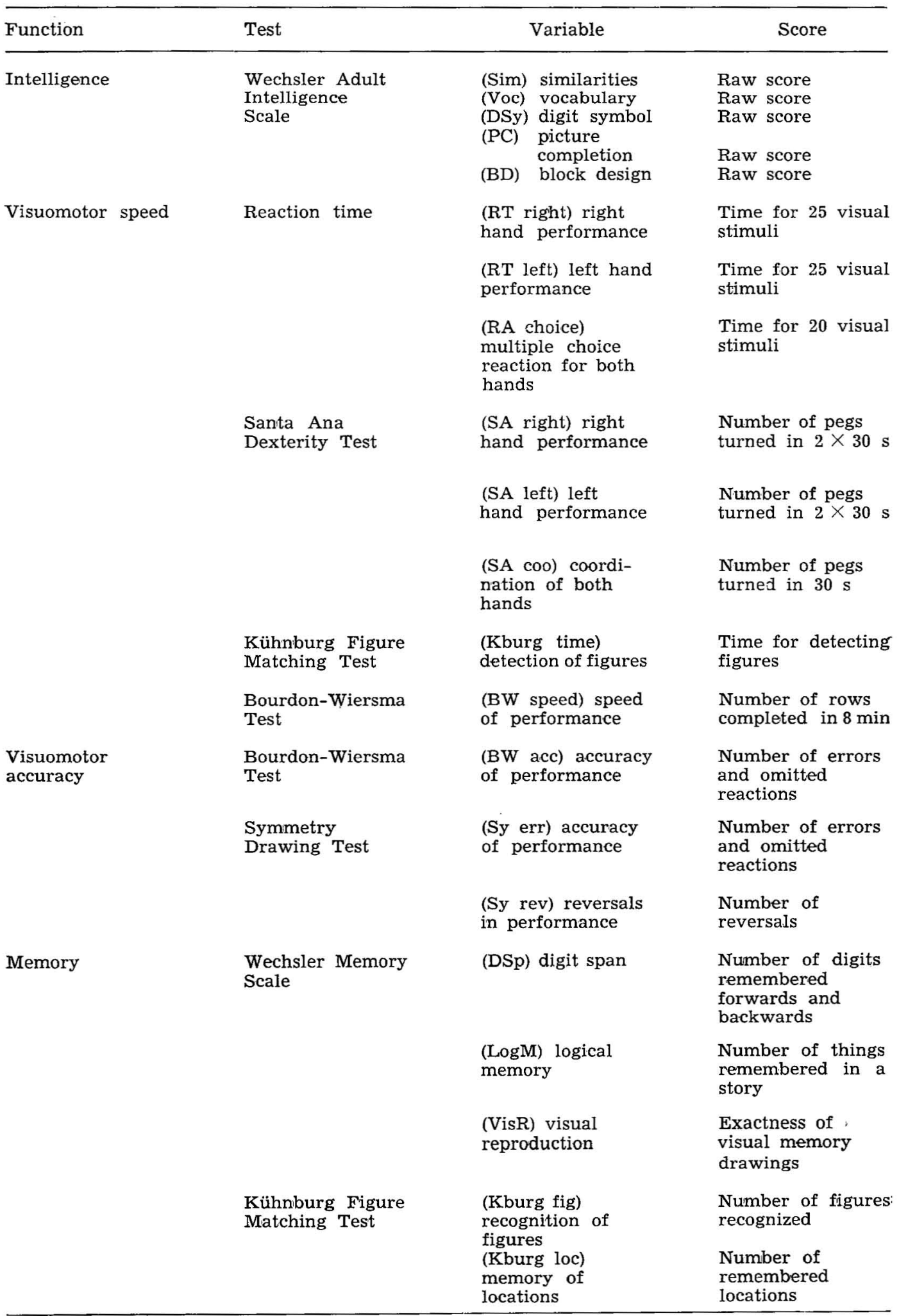


Table 1. (continued)

\begin{tabular}{|c|c|c|c|}
\hline Function & Test & Variable & Score \\
\hline \multirow[t]{2}{*}{ Vigilance } & $\begin{array}{l}\text { Bourdon-Wiersma } \\
\text { Test }\end{array}$ & $\begin{array}{l}\text { (BW fluct) } \\
\text { fluctuation } \\
\text { in performance }\end{array}$ & $\begin{array}{l}\text { Difference between } \\
\text { three longest and } \\
\text { three shortest } \\
\text { row times }\end{array}$ \\
\hline & & $\begin{array}{l}\text { (BW time est) } \\
\text { estimation of } \\
\text { time used in } \\
\text { performance }\end{array}$ & $\begin{array}{l}\text { Estimated time in } \\
\text { minutes }\end{array}$ \\
\hline \multirow[t]{3}{*}{$\begin{array}{l}\text { Psychomotor } \\
\text { performance }\end{array}$} & Mira test & $\begin{array}{l}\text { (Mi dist) distance } \\
\text { of straight lines }\end{array}$ & $\begin{array}{l}\text { Distance between } \\
\text { four pairs of } \\
\text { straight lines }\end{array}$ \\
\hline & & $\begin{array}{l}\text { (Mi form 1) form } \\
\text { level of straight } \\
\text { lines }\end{array}$ & $\begin{array}{l}\text { Tremor, disorgani- } \\
\text { zations, etc., in } \\
\text { drawing } \\
\text { (estimation 1-4) }\end{array}$ \\
\hline & & $\begin{array}{l}\text { (Mi form 2) form } \\
\text { level of stair- } \\
\text { cases }\end{array}$ & $\begin{array}{l}\text { Tremor, disorgani- } \\
\text { zations, etc., in } \\
\text { drawing } \\
\text { (estimation 1-4) }\end{array}$ \\
\hline \multirow[t]{4}{*}{ Personality } & $\begin{array}{l}\text { Rorschach } \\
\text { Inkblot Test }\end{array}$ & $\begin{array}{l}\text { (Ro R) produc- } \\
\text { tivity }\end{array}$ & $\begin{array}{l}\text { Number of } \\
\text { responses }\end{array}$ \\
\hline & & $\begin{array}{l}\text { (Ro rt) average } \\
\text { latency time }\end{array}$ & $\begin{array}{l}\text { Mean for latency } \\
\text { time of responses }\end{array}$ \\
\hline & & $\begin{array}{l}(\text { Ro } R e j) \\
\text { rejections and } \\
\text { shocks }\end{array}$ & $\begin{array}{l}\text { Number of tables } \\
\text { without answers }\end{array}$ \\
\hline & & $\begin{array}{l}\text { (Ro FL) form } \\
\text { level }\end{array}$ & $\begin{array}{l}\text { Form level of } \\
\text { responses }\end{array}$ \\
\hline
\end{tabular}

\section{Statistical analysis}

In comparing the psychological functions of the exposed group with those of the nonexposed group, we used Student's t-test. We also used Student's t-test to compare exposed subjects with a mean mandelic acid concentration of less than $674 \mathrm{mg} / 1$ [the estimated mandelic acid concentration corresponding to about 25 ppm 8-h time-weighted average (TWA) of styrene exposure] to those with a mean mandelic acid concentration of more than $1,762 \mathrm{mg} / 1$ (the estimated mandelic acid concentration corresponding to about 75 ppm 8-h TWA of styrene exposure) (2).

The relationship between the psychological functions and the duration and the intensity of exposure was analyzed with a stepwise multiple regression analysis (18).

\section{RESULTS}

Comparison of the exposed and nonexposed groups and the slightly and highly exposed subgroups

In a comparison with Student's t-test we found only slight differences between the mean values of the psychological functions of the exposed and the nonexposed groups. Two out of 20 differences were significant at the $p$ level of 0.05 - one out of 20 would reach this value at random. Visuomotor accuracy (Sy rev) was poorer and latency time in the Rorschach test (Ro rt) longer in the exposed group than in the nonexposed group.

In the intragroup comparison of exposed subjects with a mean mandelic acid 
Table 2. Means (M), standard deviations and significances between the two exposed subgroups.a

\begin{tabular}{|c|c|c|c|c|c|}
\hline \multirow{2}{*}{$\begin{array}{l}\text { Function/ } \\
\text { variable }\end{array}$} & \multicolumn{2}{|c|}{$\begin{array}{l}\text { Low exposure } \\
\text { group }(\mathbf{N}=36)\end{array}$} & \multicolumn{2}{|c|}{$\begin{array}{l}\text { High exposure } \\
\text { group }(N=19)\end{array}$} & \multirow{2}{*}{$\begin{array}{l}\text { Statistical significance } \\
\text { (one-way) } \\
\text { corresponding to } \\
\text { Student's t-test }\end{array}$} \\
\hline & $\mathrm{MI}$ & SD & $\mathrm{M}$ & SD & \\
\hline $\begin{array}{l}\text { Visuomotor } \\
\text { accuracy }\end{array}$ & $\cdot$ & & & & \\
\hline $\begin{array}{l}\text { BW acc } \\
\text { Sy rev }\end{array}$ & $\begin{array}{r}14.5 \\
3.4\end{array}$ & $\begin{array}{r}10.0 \\
2.5\end{array}$ & $\begin{array}{r}23.6 \\
6.4\end{array}$ & $\begin{array}{r}17.0 \\
3.7\end{array}$ & $\begin{array}{l}<0.02 \\
<0.01\end{array}$ \\
\hline $\begin{array}{l}\text { Psychomotor } \\
\text { performance } \\
\text { Mi dist } \\
\text { Mi form } 1\end{array}$ & $\begin{array}{r}130.7 \\
1.9\end{array}$ & $\begin{array}{r}27.9 \\
0.8\end{array}$ & $\begin{array}{r}143.4 \\
\quad 2.5\end{array}$ & $\begin{array}{r}24.7 \\
1.1\end{array}$ & $\begin{array}{l}<0.10 \\
<0.05\end{array}$ \\
\hline $\begin{array}{l}\text { Personality } \\
\text { FL }\end{array}$ & 9.9 & 1.6 & 10.9 & 2.0 & $<0.05$ \\
\hline
\end{tabular}

a Only variables with statistically significant differences between group means are included.

concentration of less than $674 \mathrm{mg} / 1$ $(\mathrm{N}=36)$ and those whose mean concentration was more than $1,762 \mathrm{mg} / \mathrm{l}$ $(\mathrm{N}=19)$, visuomotor inaccuracy (BW acc and Sy rev) and poor psychomotor performance (Mi dist and Mi form 1) characterized the group with the higher exposure (table 2). However, the form level of responses (Ro FL) was better in this group (at $\mathrm{p}<0.05$ level).

\section{Psychological functions and duration of exposure}

The relationship between the psychological functions and the duration of styrene exposure can be seen in table 3 , in which the results of the stepwise multiple regression analysis are presented. Because of its statistically significant correlation to the duration of exposure $(r=0.38)$ age was included as a fixed predictor along with the psychological variables that were subjected to stepwise selection. Two test variables were selected that increased "significantly" $(p<0.05)$ the covariance between the duration of exposure and the "predictor" set of variables. These test variables were one visuomotor speed variable (Kburg time) and one memory variable (Kburg fig). Their joint partial correlation with the duration of exposure, when the effect of age was eliminated, was $\mathrm{R}=0.28, \mathrm{p}<0.05$.
Psychological functions and intensity of styrene exposure

In the stepwise multiple regression analysis of the psychological functions and the intensity of exposure (mean of mandelic acid concentration), both untransformed $(\mathrm{mg} / \mathrm{l})$ and transformed $[\ln (x+100)]$ values of the latter were used. The results from the analysis with the untransformed values are presented in table 4 and fig. 3 .

Of the psychological functions, visuomotor inaccuracy showed the strongest relationship to mandelic acid concentration.

Table 3. Results of the multiple regression analysis of the psychological functions and duration of exposure.

\begin{tabular}{lc}
$\begin{array}{l}\text { Function/ } \\
\text { variable }\end{array}$ & $\begin{array}{c}\text { Standardized regression } \\
\text { coefficient }\end{array}$ \\
\hline $\begin{array}{l}\text { Age } \\
\text { Memory } \\
\quad \text { Kburg fig }\end{array}$ & $0.34^{* * *}$ \\
$\begin{array}{l}\text { Visuomotor speed } \\
\text { Kburg time }\end{array}$ & $-0.21^{*}$ \\
\hline
\end{tabular}

$\mathrm{R}^{2}=0.23$

$R=0.48 \quad \mathrm{p}<0.01$ (age included)

$\mathrm{R}^{2}=0.08$
$\mathrm{R}=0.28 \quad \mathrm{p}<0.05$ (age excluded)

Significance levels of additional information: *** $\mathrm{p}<0.001 ; * \mathrm{p}<0.05$. 


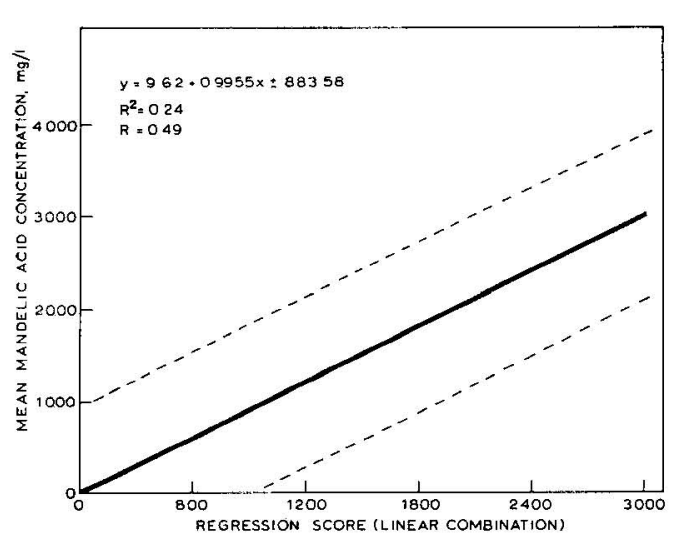

Fig. 3. Relationship between mean mandelic acid concentration and the regression score (linear combination of four test variables).

Visuomotor inaccuracy and high mandelic acid concentration were related. Errors and omitted reactions in the Bourdon-Wiersma Test and reversals in the Symmetry Drawing Test were predicting variables. Psychomotor performance (Mi dist) and vigilance (BW time est) were also slisihtly related to mandelic acid concentration. Disturbances in these three psychological functions explained about $25 \%$ of the variability in mandelic acid concentration $(R=0.49, p<0.01)$. After logarithmic transformations were made for mandelic acid concentration and the visuomotor accuracy variables, the multiple correlation coefficient dropped to $R=0.41$ because in some extreme cases exposure and psychological disturbances were highly congruent when the untransformed values were used.

\section{Psychological functions and cumulative dose of exposure}

In addition to treating the duration and the intensity of exposure separately, we combined the two into a rough measure of cumulative dose, namely, the product of duration of exposure (years) and the mean mandelic acid concentration $(\mathrm{mg} / \mathrm{l})$, and subjected the dose to a regression analysis similar to that used for the two individually. The results are presented in table 5. Visuomotor inaccuracy (Sy err and $\mathrm{BW}$ acc) showed a statistically significant relationship to exposure dose, but long latency time in the Rorschach test was even more closely related. The latter variable can be interpreted as a high level of inhibition. Age accompanied the psychological variables in the analysis because of its statistically significant correlation with the exposure variable used $(r=0.27)$.

Table 4. Results of the multiple regression analysis of mandelic acid concentration ( $\mathrm{mg} / \mathrm{l})$ and psychological functions.

\begin{tabular}{|c|c|}
\hline $\begin{array}{l}\text { Function/ } \\
\text { variable }\end{array}$ & $\begin{array}{l}\text { Standardized regression } \\
\text { coefficient }\end{array}$ \\
\hline $\begin{array}{l}\text { Visuomotor accu } \\
\text { BW acc } \\
\text { Sy rev }\end{array}$ & $\begin{array}{l}0.28^{* *} \\
0.26^{* *}\end{array}$ \\
\hline $\begin{array}{l}\text { Psychomotor per } \\
\text { Mi dist }\end{array}$ & $0.14^{*}$ \\
\hline $\begin{array}{l}\text { Vigilance } \\
\text { BW time est }\end{array}$ & $-0.14^{*}$ \\
\hline $\begin{array}{l}\mathrm{R}^{2}=0.24 \\
\mathrm{R}=0.49\end{array}$ & $\mathrm{p}<0.01$ (linear) \\
\hline $\begin{array}{l}\mathrm{R}^{2}=0.17 \\
\mathrm{R}=0.41\end{array}$ & $\mathrm{p}<0.01$ (In $(\mathrm{x}+100)$ trans- \\
\hline
\end{tabular}

Significance levels of additional information: ${ }^{* *} \mathrm{p}<0.01 ;{ }^{*} \mathrm{p}<0.13$.

Table 5. Results of the multiple regression analysis of cumulative exposure dose (duration $X$ intensity) and the psychological functions.
Function/ variable

\begin{tabular}{ll}
\hline Age & $0.25^{* *}$ \\
Personality & \\
Ro rt & $0.24^{*}$ \\
Visuomotor accuracy & $0.20^{*}$ \\
Sy err & $0.20^{*}$ \\
BW acc & \\
Vigilance & -0.16 \\
BW time est & \\
\hline
\end{tabular}

$\mathrm{R}^{2}=0.26$

$\mathrm{R}=0.53 \quad \mathrm{p}<0.01$ (age included)

$\mathrm{R}^{2}=0.16$

$R=0.40 \quad p<0.01$ (age excluded)

Significance levels of additional information: $* * \mathrm{p}<0.01 ; * \mathrm{p}<0.05$. 
Pathological findings in psychological functions and the intensity of exposure

Since the intensity of exposure showed the greatest relationship to psychological functions, especially for visuomotor accuracy, we examined the relationship between pathological findings in psychological functions and mandelic acid concentration. We considered a psychological function to be pathological when the subjects' scores on the tests differed by more than $1 \mathrm{SD}$ from the mean of the exposed group.

Two groups were formed for every function, namely, those with at least one functional disturbance (as defined by a score differing from the mean by at least $1 \mathrm{SD}$ in the "diagnostic" direction) and those with no such functional disturbance. In addition we formed a "total disturbance score" by adding together the 10 transformed test scores, listed in table 6 . The transformation took the following form for each test variable: $\mathbf{0}=$ difference $(\triangle)$ between the individual test score and the mean of the exposed group in the same test less than $1 \mathrm{SD}$ in the "diagnostic" direction; $1=\mathrm{SD} \leq \triangle<2 \mathrm{SD}$; and $2=\triangle \geq 2 \mathrm{SD}$

Every function was represented by two separate variables, chosen according to

Table 6. Construction of composite scores and the correlation between total IQ and the test variables.

Function/variable
Correlation to
total IQ (r)

$\begin{array}{cc}\text { Visuomotor speed } & \\ \text { RT right } & 0.35^{\mathrm{a}} \\ \text { SA right } & -0.20 \\ \text { Visuomotor accuracy } & -0.14 \\ \text { BW err } & -0.25 \\ \text { Sy rev } & \\ \text { Memory } & 0.40^{\mathrm{a}} \\ \text { Log M } & 0.45^{\mathrm{a}} \\ \text { Vis R } & \\ \text { Vigilance } & -0.26 \\ \text { BW fluct } & -0.14 \\ \text { BW time est } & \\ \text { Psychomotor performance } & 0.15 \\ \text { Mi dist } & -0.18 \\ \text { Mi form 2 } & \end{array}$

a Correlation with total IQ taken into account. previous experience. We did not include intelligence as such in the analysis. Instead. it was taken into account in functions. significantly correlated with it. Both memory variables and one visuomotor speed variable (RT right) correlated positively and statistically significantly with the total IQ, determined with six subtests from the Wechsler Adult Intelligence Scale. In table 6 the construction of the combined scores and the correlations between the test variables and total IQ are presented. Personality variables were not included in this phase of the analysis.

The mean of the mandelic acid concentration of the subjects with one or more disturbance score for a psychological function was compared to the mean of the mandelic acid concentration of the group without any disturbance for the same function. The results are presented in table 7. Severe disturbances were few. The correlation coefficient between the total disturbance score and the mean mandelic acid concentration was $r=0.26$ $(p<0.05)$. Earlier results of the study were therefore supported, because visuomotor inaccuracy and high mandelic acid concentration had been shown to be related $(\mathrm{p}<0.01)$. The mean concentration for the group with normal visuomotor accuracy was $761 \mathrm{mg} / \mathrm{l}$, and that for the group with inaccurate visuomotor performance was $1,325 \mathrm{mg} / 1$. A slight relationship between slowed visuomotor speed and high exposure was also suggested $(p<0.10)$. The age and the duration of exposure of subjects with pathological findings were similar to those of subjects with no disturbances in psychological functions.

\section{DISCUSSION}

The comparison between exposed and nonexposed workers revealed very few statistically significant differences. Visual inaccuracy (Sy rev) and a high level of inhibition (Ro $\mathrm{rt}$ ) characterized the exposed group. In general this comparison showed that the exposed group did not as a whole have many severe disturbances.

The comparison between the low and high exposure subgroups revealed the most differences. Those having a mean 
Table 7. Geometric means and standard deviations of mandelic acid concentration for two subgroups of the exposed workers and the significance between the subgroup means.

\begin{tabular}{|c|c|c|c|c|c|c|c|}
\hline \multirow{3}{*}{ Function } & \multicolumn{6}{|c|}{ Mandelic acid concentration } & \multirow{3}{*}{$\begin{array}{c}\text { Statistical } \\
\text { significance } \\
\text { (one-way) } \\
\text { corresponding } \\
\text { to Student's } \\
\text { t-test }\end{array}$} \\
\hline & \multicolumn{3}{|c|}{ Disturbance score $=0$} & \multicolumn{3}{|c|}{ Disturbance score $=1-$} & \\
\hline & $\mathrm{N}$ & Geom.mean & $\mathrm{SD}$ & $\mathbf{N}$ & Geom. mean & $\mathrm{SD}$ & \\
\hline Visuomotor speed & 77 & 804 & 984 & 21 & 1,179 & 1,043 & $<0.10$ \\
\hline Visuomotor accuracy & 74 & 761 & 740 & 24 & 1,326 & 1,411 & $<0.01$ \\
\hline Memory & 72 & 820 & 911 & 26 & 1,036 & 1,231 & NS \\
\hline Vigilance & 61 & 885 & 868 & 37 & 852 & 1,212 & NS \\
\hline Psychomotor performance & 73 & 819 & 877 & 25 & 1,048 & 1,261 & NS \\
\hline
\end{tabular}

mandelic acid concentration of more than $1,762 \mathrm{mg} / 1$ showed visuomotor inaccuracy and poor psychomotor performance.

We applied many parallel statistical methods in the analysis of the relationship between psychological functions and the duration and intensity of exposure. Duration of exposure had only a slight relationship to disturbances in psychological functions. One measure of visuomotor speed and one measure of visual memory correlated with the duration of exposure. The positive correlation $(p<0.01)$ between exposure duration and chronological age complicated the analysis.

High mandelic acid concentration was statistically significantly related to visuomotor inaccuracy and to poor psychomotor performance and lowered vigilance. Poor performance for four psychological variables explained one-fourth of the variability in mandelic acid concentration in the multiple regression analysis. When the scores of the disturbances in different psychological functions were used, the earlier results were confirmed. Visuomotor inaccuracy was again related to a high mandelic acid concentration. Poor visuomotor speed was also slightly related to a high mandelic acid concentration. Thus a high mandelic acid concentration was related to visuomotor inaccuracy, and it had a slight relationship to visuomotor speed, vigilance, and psychomotor performance.

The product of the two exposure indicators, duration and intensity, provided very little additional information. Poor visuomotor accuracy and one Rorschach variable, long latency time in answering, was related to a high cumulative dose of exposure. The latter variable was interpreted as indicating a high level of inhibition.

When the results of the present study are compared with earlier psychological studies dealing with the adverse effects of long-term occupational exposure to solvents $(8,12,13)$, the adverse effects of styrene are slighter and they occur in a narrower range of psychological functions. This result is understandable because the subjects of the earlier studies had either been diagnosed as having an occupational disease or they suffered from marked subjective symptoms. The present subjects were an unselected group of workers exposed to styrene, and they had not come to the examination because of suspicion of disease. In addition their duration of exposure was not so long as that in the earlier studies. The present study was concerned with revealing subclinical symptoms and findings associated with styrene exposure. For example, we found no subject with an organic psychosyndrome among this group of workers as was found among the subjects of earlier studies. Disturbances were limited primarily to visuomotor inaccuracy, but there was also some evidence of other disturbances.

A comparison between the results of the present study and the other studies dealing with occupational styrene exposure $(6,7)$ is difficult because of the differences in the methods used. In the present study reaction time, which was prolonged in two earlier studies in exposed groups, had only a slight relationship to mandelic acid concentration when values indicating 
clear disturbances were used. It must be kept in mind however that the reaction time measurements in the study of Gamberale and coworkers (6) were based on a longer duration of experiment than that used in this study. Furthermore we based the analysis of the reaction time measurements on the relationship between reaction time and the intensity of exposure; we did not make a group comparison as in the earlier studies because reaction time measurements from the nonexposed group were not available. However, speed dependent variables were almost completely uncorrelated with exposure measurements in our study.

Earlier studies concerning short-term styrene exposure have shown that speed performances slow with high exposure $(5,7,14)$. The present study of occupational exposure stressed, on the contrary, disturbances in visuomotor accuracy, especially when mandelic acid concentration was used as the indicator of styrene exposure.

The problems in this study, as in nearly all cross-sectional studies, have been related to the adequacy of the comparison group and the choice of appnopriate test methods. The comparison group was chosen mainly because of its suitable age distribution, educational level, and existing knowledge about work conditions. Including more than one comparison group would have been safer and might have revealed some of the possible limitations and distortions which might have occurred with one comparison group. The inclusion of two groups was not however possible. Test methods measuring vigilance and personality were not satisfactory. Vigilance was determined with short-time measurements, although the nature of vigilance calls for a long measurement period. The Rorschach test was the only measurement of personality and only four formal variables, quite difficult to interpret, were used. The personality trait variables from the Rorschach test were not used because of the already otherwise large number of variables, but the results from that test should be considered separately.

Because the present study, as other earlier studies, has been cross-sectional, little can be said about the duration of the psychological findings. In any case the findings were more chronic than acute because at least $20 \mathrm{~h}$ elapsed between the last exposure and the psychological examination. Also the indicators of styrene exposure reflected past exposure more than a short-time and present exposure. Longitudinal studies are needed to explain the duration of these findings.

The correlation between mandelic acid concentration and disturbances in psychological function yielded some evidence of a dose-response relationship. The establishment of a good linear relationship would be quite improbable however because of the duration of the exposure, the selection occurring among workers, and the complexity of the psychological functions under study. The usefulness of the results is especially apparent when group diagnoses are made for exposed populations, e.g., when additional information is needed for the determination of threshold limit values. The observed lowered visuomotor accuracy has significance not only for occupational safety but also for traffic safety at the end of the work day.

\section{REFERENCES}

1. BLEULER, M. Grundsätzliches über psychische Giftschäden. Schweiz. med. Wochenschr. 74 (1944) 923-928.

2. ENGSTRÖM, K., HÄRKÖNEN, H., KALLIOKOSKI, P. and RANTANEN, J. Urinary mandelic acid concentration after occupational exposure to styrene and its use as a biological exposure test. Scand. $j$. work environ. \& health 1 (1976) 21-26.

3. ENGSTRÖM, $K$. and RANTANEN, J. A new gas chromatographic method for determination of mandelic acid in urine. Int. Arch. Arbeitsmed. 33 (1974) 163-167.

4. GAMBERALE, F. and HULTENGREN, M. Exposition för toluen: Psykofysiologiska funktioner (AI-rapport no. 20). Arbetarskyddsverket, Stockholm 1972. $46 \mathrm{p}$.

5. GAMBERALE, F. and HULTENGREN, M. Exposition för styren: Psykofysiologiska funktioner (Arbete och hälsa no. 3). Arbetarskyddsverket, Stockholm 1973. $61 \mathrm{p}$.

6. GAMBERALE, F., LISPER, H. O. and ANSHELM-OLSEN, B. Styrengasers effekt på reaktionsförmåga hos arbetare $i$ plastbåtindustri (Arbete och hälsa no. 8). Arbetarskyddsverket, Stockholm 1975. $23 \mathrm{p}$.

7. GÖTELL, P., AXELSSON, O. and LINDELÓF, B. Field studies in human styrene exposure. Work-environ-health 9 (1972) $76-83$. 
8. HÄNNINEN, H. Psychological picture of manifest and latent carbon disulfide poisoning. Br. j. ind. med. 28 (1971) $374-381$.

9. HÄNNINEN, H. Psychological tests used in toxicopsychological studies at the Institute of Occupational Health. (Reports from the Institute of Occupational Health no. 74). Institute of Occupational Health, Helsinki 1972. $34 \mathrm{p}$.

10. HÄNNINEN, H. Behavioral study of the effects of carbon disulfide. In: C. XINTARAS, B. L. JOHNSON and I. DE GROOT (eds.), Behavioral toxicology. U.S. Department of Health, Education and Welfare, Washington, D.C. 1974, pp. 73-80.

11. HÄRKÖNEN, H., KALLIOKOSKI, P., HIETALA, S. and HERNBERG, S. Concentration of mandelic and phenylglyoxylic acid in urine as indicator of styrene exposure. Work-environ.-health 11 (1974) $162-169$.

12. LINDSTRÖM, $K$. Psychological performances of workers exposed to various solvents. Work-environ.-health 10 (1973) 151 -155 .

13. MÜNCHINGER, R. Der Nachweis zentralnervöser Störungen bei lösungsmittelexponierten Arbeitern. Proceedings of the 14th international congress on occupational health, Madrid 1963, pp. 687-689.

14. OLTRAMARE, M., DESBAUMES, E., IMHOFF, C. and MICHIELS, W. Toxicologie du styrene monomere (Editions Médecine et hygiéne). Geneva 1974. $100 \mathrm{p}$.

15. SALVINI, M., BINASCHI, S. and RIVA, M. Evaluation of the psychophysiological functions in humans exposed to the "Threshold Limit Value" of 1, 1, 1-trichloroethane. $\mathrm{Br} . j$. ind. med. 28 (1971) $286-292$.

16. STEWART, R. D., DODD, H. C., BARETTA, E. D. and SCHAFFER, A. W. Human exposure to styrene vapor. Arch. environ. health 16 (1968) 565-662.

17. STEWART, R. D., BARETTA, E. D. DODD, H. C. and TORKELSON, T. R. Experimental human exposure to tetrachloroethylene. Arch. environ. health 20 (1970) $225-229$.

18. VAN DE GEER, J. P. Introduction to multivariate analysis for the social sciences. Freeman and company, San Fransisco, Calif. 1972. 293 p.

19. VERNON, R. J. and FERGUSON, R. K Effects of tricloroethylene on visualmotor performance. Arch. environ. health 18 (1969) $894-900$.

Received for publication: 1976-03-08 